\title{
Cow's Milk Allergy: Management and Prevention
}

\author{
Giampaolo Ricci*, Elisabetta Calamelli
}

Department of Medical and Surgical Sciences, Pediatric Unit, S. Orsola-Malpighi Hospital, University of Bologna, Bologna, Italy

Corresponding author: Ricci, G. Department of Medical and Surgical Sciences, Pediatric Unit, S. Orsola-Malpighi Hospital, University of Bologna, Massarenti, Bologna, Italy. Tel : +390516363075; Fax : +390516363075; E-mail: giampaolo.ricci@unibo.it

\begin{abstract}
Cow's milk allergy (CMA) is one of the most frequent food allergies in childhood with an estimated prevalence of $2 \%$ in infants. As observed in the natural course of this disease, CMA has a good prognosis and more than half of the children reach the tolerance before school age. Otherwise, many different factors can modulate the natural history of CMA. Clinical and laboratory data suggest that many endotypes and phenotypes can be individuated with different evolutions towards tolerance. For these reasons physicians need to identify these different patterns to better choose the therapeutic pathway for each patient. Another aspect is represented by the developing strategies of primary prevention of CMA, such as dietary interventions both in the mother (during pregnancy and/ or lactation), and, in absence of breast milk, also in high risk infants, through the use of extensive or partial hydrolyzed milk formula. Nevertheless many studies have been carried out, up today the available data are still conflicting and more robust results should be reported. The aim of this review article is to give practical advices in the diagnosis, management and prevention of CMA in childhood, according to the most recent guidelines and consensus documents.
\end{abstract}

Citation: Ricci, G. Cow's Milk Allergy: Management and Prevention.(2015) J Food Nutr Sci 2(2): 92-97.

DOI: $10.15436 / 2377-0619.15 .013$

\section{Introduction}

The aim of this paper is to give some synthetic and practical advices in the management of cow's milk allergy (CMA) in children after a complete and extensive revision of the different items involving this disease reported in the most recent guidelines and consensus documents. Moreover some new data published just in these days on prevention will be described in summary.

\section{Epidemiology}

CMA is one of the most frequent food allergies (FA) in infants and children; its prevalence varies according to different studies, since there are conflicting data between symptoms reported by patients and the diagnosis of FA made through an oral food challenge (OFC). Moreover, the frequencies of FA varies in the different age groups, but overall is also different according to the assessment methods used. The pooled age-stratified prevalence of CMA has been recently reviewed and reported in the guidelines of the European Academy of Allergy and Clinical Immunology (EAACI) ${ }^{[1]}$. These data are summarized in Table 1, according to the different assessment methods: self-reported diagnosis, presence of specific IgE (sIgE) against CMA, presence of a positive skin prick test (SPT) and response of OFC. Anyway, these data show that the prevalence of CMA confirmed by an OFC with CMA is about $2 \%$ in infants. 
Table1: The estimated pooled prevalence of cow's milk allergy in studies published in Europe between January 2000 and September 2012, modified from the most recent guidelines of the European Academy of Allergy and Clinical Immunology ${ }^{[1]}$.

\begin{tabular}{|l|l|l|l|l|}
\hline & Self reported & IgE positive & $\begin{array}{l}\text { Skin prick } \\
\text { test positive }\end{array}$ & $\begin{array}{l}\text { Oral food } \\
\text { Challenge }\end{array}$ \\
\hline $0-1$ years & 4.2 & 1.6 & & 2 \\
\hline 2-5 years & 3.75 & 6.8 & & 0.35 \\
\hline $6-17$ years & 1.37 & 2.1 & & 0.15 \\
\hline$>18$ & 2.14 & & 0.33 & 0.21 \\
\hline all & 2.28 & 4.6 & 0.33 & 0.61 \\
\hline
\end{tabular}

\section{The Natural History}

The natural history of milk allergy is generally encouraging, with the greater part of children achieving tolerance during childhood. In a previous study by Host and Halken ${ }^{[2]}$ the percentage of children who recovered from CMA at 3 years of age was $87 \%$. Less optimistic data where reported by Saarinen et $\mathrm{a}^{[3]}$ : only $74 \%$ of patients achieve tolerance at 5 years in IgE-mediated CMA and $85 \%$ at $8 / 9$ years. Data from patients referred to specialist clinics are still less comfortable: Skripack ${ }^{[4]}$ found that only $19 \%$ of patients at 4 years and $52 \%$ at 10 years had undergone CMA. Also Vantoet $\mathrm{a}^{[5]}$ observed a slower trend in achieving tolerance and a higher percentage of children with disease persisting till adolescence and even adulthood.

In a recent observational study ${ }^{[6]}$, out of 512 infants enrolled from 3 to 15 months of age, 244 had a diagnosis of CMA at baseline. At the last follow-up visit (median age 66 months) only $54 \%$ of these children had undergone CMA, but there was statistically significant difference if the baseline sIgE level to $\mathrm{CM}$ was $<2 \mathrm{kUA} / \mathrm{L}$ or $>10 \mathrm{kUA} / \mathrm{L}$. In the first case the tolerance was reached in about $72 \%$ of children, in the second only in $23 \%$ of them. A similar trend was also observed evaluating a SPT (Skin Prick Test) wheal diameter $<5 \mathrm{~mm}$ of or $>10 \mathrm{~mm}$. An interesting trend was shown in children with coexistent atopic dermatitis (AD): CMA was resolved in $81 \%$ of patients without $\mathrm{AD}$, instead in presence of a mild form in about $65 \%$ of cases, while severe forms of AD showed a recovery only in $46 \%$ of cases. These data suggest that not only the level of allergic sensitization affects the course of this disease, but also the presence of AD significantly influence its evolution. Indeed, different endotypes and phenotypes drive the natural course of CMA and these specific characteristics are determinants to give a prognosis to patients and their families.

\section{Diagnosis of Cow Milk Allergy (CMA) The Allergenic Proteins}

To understand the diagnostic tools nowadays available for the diagnosis of CMA, it is important to recall some biochemical characteristics of the milk proteins. CM is composed of about 20 proteins, but only three of them are the major allergens implicated in the clinical manifestations of the disease: $\alpha$-lactalbumin (ALA), $\beta$-lactoglobulin (BLG) and casein ${ }^{[7,8]}$. The main characteristics of these proteins are shown in Table 2 . It is important to underline that ALA, BLG are heat-sensitive, even in different grades, while caseins are stable to heat.
Table 2: Main biochemical and immunological characteristics of cow's milk allergens, modified from Hochwallner ${ }^{[7]}$ and the allergome database ${ }^{[8]}$

\begin{tabular}{|c|c|c|c|c|c|}
\hline & Protein & $\begin{array}{l}\text { Allergen } \\
\text { name }\end{array}$ & $\begin{array}{l}\text { Conc } \\
(\mathrm{g} / \mathrm{L})\end{array}$ & $\begin{array}{l}\text { Biological } \\
\text { function }\end{array}$ & $\begin{array}{l}\text { No.of } \\
\text { aa/mole- } \\
\text { cule }\end{array}$ \\
\hline \multirow[t]{5}{*}{$\begin{array}{l}\text { Whey } \\
(20 \%)\end{array}$} & $\begin{array}{l}\text { a-lactalbu- } \\
\text { min }\end{array}$ & Bos d 4 & $1-1.5$ & albumin & 123 \\
\hline & $\begin{array}{l}\text { b-lactoglob- } \\
\text { ulin }\end{array}$ & Bos d 5 & $3-4$ & $\begin{array}{l}\text { globulins } \\
\text { lipocalins }\end{array}$ & 162 \\
\hline & $\begin{array}{l}\text { Bovin serum } \\
\text { albumin }\end{array}$ & Bos d 6 & $0.1-0.4$ & albumin & 582 \\
\hline & $\begin{array}{l}\text { Immuno- } \\
\text { globulins }\end{array}$ & Bos d 7 & $0.6-1$ & $\begin{array}{l}\text { immunoglob- } \\
\text { ulins }\end{array}$ & \\
\hline & Lactoferrin & & 0.09 & & 703 \\
\hline \multirow{5}{*}{$\begin{array}{l}\text { Whole } \\
\text { casein } \\
(80 \%)\end{array}$} & caseins & Bos d 8 & & casein & \\
\hline & $\alpha \mathrm{S} 1$-casein & Bos d 9 & $12-15$ & & 199 \\
\hline & $\alpha \mathrm{S} 2$-casein & Bos d 10 & $3-4$ & $\begin{array}{l}\text { important role } \\
\text { in the capac- } \\
\text { ity of milk to } \\
\text { transport calci- } \\
\text { um phosphate }\end{array}$ & 207 \\
\hline & $\beta$-Casein & Bos d 11 & $9-11$ & & 209 \\
\hline & к-Casein & Bos d 12 & $3-4$ & & 169 \\
\hline
\end{tabular}

\section{The Gold Standard Method}

As for all the allergic conditions, the cornerstone of the diagnosis is the demonstration of a clear relationship between clinical symptoms and the presence of sIgE against the implicated allergen. In practice, a diagnosis of CMA should be performed after an elimination diet followed after 2-3 weeks by an OFC which is the gold standard method. Physicians should use this method not only in experimental studies but also in clinical practice. However, in many worldwide countries performing an OFC is impossible for practical reasons, first of all to costs. The DRACMA (Diagnosis and Rationale for Action against Cow's Milk Allergy) guidelines ${ }^{[9]}$ aimed to facilitate the diagnosis of CMA with a reproducible flow-chart, identifying the cut-off values for both SPT and SIgE to CM with the higher negative and positive predictive values for OFC. However this approach does not replace the OFC that remain the best diagnostic option to be performed whenever available. In future the test should be performed, in the "grey zone", when the predictive values are in the middle ranges and not useful as diagnostic tools. The DRACMA guidelines, using the GRADE method, identified as the lower cut-off values a wheal diameter of the SPT of $3 \mathrm{~mm}$ and $\mathrm{sIgE}$ to $\mathrm{CM}$ of $0.35 \mathrm{IU} / \mathrm{L}$ (CAP-RAST or FEIA method). Under these values a diagnosis of CMA is unlikely, and the OFC is not necessary. On the other hand, when the wheal diameter of the SPT is greater than $12 \mathrm{~mm}$ and /or SIgE to CM (CAP-RAST or FEIA method) is greater than $10 \mathrm{KU} / \mathrm{L}$ the probability to have CMA is very high and the OFC might be omitted. These guidelines aid the physician to select patients who really need to perform an OFC, and probably also to avoid elimination diets when not strictly necessary.

Another possible tool useful to foresee the outcome of an OFC could be represented by the so-called end-point prick test (EPT). This technique is the same of a SPT, employing different and progressive dilutions of fresh milk. In a previous paper 
by our group involving children with previous or current CMA evaluated with $\mathrm{OFC}^{[10]}$, we have observed that the positive result of the EPT over the dilution of 1:100.000 has a positive predictive value of $100 \%$ with all children with this feature showing a positive OFC. Indeed, this test could be useful to avoid OFC in selected patients at higher risk to develop severe reactions during OFC. We also found that $95 \%$ of children with skin positivity up to the dilution of 1:1000 were tolerant. Interestingly, we observed that children who achieved the oral tolerance used to maintain SPT reactivity for many months.EPT is a safe and cheap test, easy to perform and without risk of adverse reactions and could be useful to identify children with a lower risk of reactions and to help physicians in the decision to perform or postpone an OFC. Moreover, it could be a valid approach to improve the use of the SPT in the diagnosis of FA and is more useful than SPT alone, especially for children in the first year of life, because it is less influenced by the operator.

Now a days, another available diagnostic tool is supplied by the advancements in the field of molecular allergology with the so-called of component resolved diagnosis (CRD). With this diagnostic assay is possible to individuate which allergenic component (protein epitope present in a food) is the elicitor of a sIgE response. Considering the different physical and biochemical characteristics of ALG, BLG and caseins, this test allow to individuate further different phenotypes of children with CMA. The presence of sIgE against only BLG (heat labile protein) is a favorable condition since children may tolerate heated milk. On the other hand, the presence of $\operatorname{sIgE}$ against caseins is a negative prognostic factor since casein-sensitized children have a high probability to have symptoms after ingestion of CM. For these reasons component $\mathrm{sIgE}$ is an available prognostic tool used to perform before OFC.

Further more, a recent paper have shown that children with CMA may have different clinical problems depending on their tolerance to heated and unheated milk ${ }^{[11]}$. Kim et al., investigating the tolerance rate to baked milk (inside a muffin), baked cheese (pizza) and unheated milk in 88 children with CMA, found that subjects who were initially tolerant to baked milk were almost 28 times more likely to become tolerant even to unheated milk compared with baked milk-reactive subjects ( $\mathrm{P}$ $<0.001)$. Moreover, subjects who used to incorporate in their diet baked milk-based foods were 16 times more likely to become unheated milk tolerant than the comparison group $(\mathrm{P}<.001)$. These clinical data were supported by the laboratory finding that casein IgG4 levels significantly increase in the baked milk-tolerant group $(\mathrm{P}<.001)$, while $\mathrm{CM}$ sIgE values did not change significantly, suggesting that the change in IgG4 production could be a marker for tolerance acquisition. Therefore, tolerance to baked milk could be considered as a marker of transient IgE-mediated cow's milk allergy, whereas reactivity to baked milk identified a more persistent phenotype. These results are important because reinforce the data that in children with CMA is important to perform OFC also with heated milk because the implementation with baked milk based foods to the diet seems to accelerate the development of tolerance to unheated milk if compared with a strict avoidance regimen.

\section{Management}

As observed in the natural course of the disease, CMA have a good prognosis and more than half of the children reach the tolerance before school age. This condition could induce physicians to have a waiting approach until this age, maintaining an avoidance diet and evaluating the tolerance status of the child every year with an OFC (also with heated milk). After this age the "waiting attitude" may be replaced by oral immunotherapy (OIT). One of the first attempt to desensitize children with severe IgE-mediated CMA was performed by Meglio et al. in a period of 6 months by introducing increasing daily doses of $\mathrm{CM}^{[12]}$. These results encouraged other studies, such as those carried out by Longo et al. who evaluated children with severe $\mathrm{CMA}^{[13]}$. In this study $36 \%$ of the treated children were able to ingest $\mathrm{CM}$ and dairy products after 1 year of OIT, with significant difference respect the control group $(\mathrm{P}<.001)$; another $50 \%$ of children didn't achieve the tolerance but became able to ingest considerably higher amounts of CM than the control group. Successively, further studies were performed and a recent systematic review and meta-analysis ${ }^{[14]}$ evaluated the randomized controlled trials performed on the efficacy of OIT in patients with CMA. Up today, although some data are encouraging, local adverse side effects as well as systemic and potentially severe and life threatening reactions during the course of OIT are still common. The available studies suggest that in children with CMA the OIT increases the probability of achieving tolerance compared to elimination diet alone, but this procedure should be considered still now a research procedure, and not to be applied in the clinical set as a routine treatment; probably only high specialized centers with an expert staff and adequate equipment should carry on this procedure with defined clinical protocols approved by the local ethical committee.

\section{Prevention}

The efforts to prevent the development of allergic disease has been carried on in many studies, through dietary interventions both in the mother (during pregnancy and/ or lactation), and, in absence of breast milk, also in the infant using special formula and then modulating the timing of introduction of complementary foods. Up today, many data are available but often conflicting (references?). Recent guidelines have tried to give, when possible, clear indications about the advices to suggest to those families considered at "high risk" to have an allergic child.

\section{Pregnancy}

The hypothesis that some allergens can traverse the placental barrier and then passover from the mother to the fetus has been suggested, favoring some studies on maternal dietary antigen avoidance during pregnancy. Most of these studies have been recently reviewed on a Cochrane metanalysis published on 2012 that did not find a protective effect of maternal antigen avoidance on the incidence of atopic diseases in children ${ }^{[15]}$. On the contrary, authors postulated that a restricted diet during pregnancy could have negative aspects. On the one hand, maternal avoidance diet was associated with a slightly but statistically significant minor mean gestational weight gain, a higher (not significant) risk of preterm birth and a decrease in mean birthweight.

On the other hand a recent paper shows that higher maternal intake of peanut, milk, and wheat during early pregnancy was associated with reduced odds of allergy and asthma in child$\operatorname{hood}^{[16]}$.

Also the maternal vitamin D status evaluated at birth in 
the cord blood seems to influence the atopic condition, even if with contrasting results. A recent study reported that lower cord blood vitamin D levels were associated with infantile eczema but not with allergen sensitization ${ }^{[17]}$. The Prediction of Allergies in Taiwanese Children (PATCH) study ${ }^{[18]}$ has tried to demonstrate the linkage among cord blood vitamin D levels, allergen sensitizations, and the development of atopic diseases. A total of 186 children were followed up for four years. The mean levels of cord blood $25(\mathrm{OH})$ Vitamin D was $23.8 \mathrm{ng} / \mathrm{mL}$ with a high prevalence of low vitamin D status $(<20 \mathrm{ng} / \mathrm{mL})$ at birth $(42 \%)$. Cord blood $25(\mathrm{OH})$ Vitamin D levels were not associated with the risk of atopic dermatitis and allergic rhinitis during childhood. In contrast, cord blood $25(\mathrm{OH})$ Vitamin D levels were inversely associated with the risk of milk sensitization at age 2 (odds ratio $2.41 ; \mathrm{P}=0.033$ ). Although there was no association between cord blood $25(\mathrm{OH})$ Vitamin D condition with mite sensitization, children with a low cord blood vitamin D status appeared to have a relatively higher prevalence of mite sensitization and a significant association with asthma by the age of 4 years.

Moreover, in an epidemiological study ${ }^{[19]}$ higher maternal intake of total dairy products, cheese, yogurt, and calcium during pregnancy may reduce respectively the risk of infantile eczema, physician-diagnosed asthma and, while higher maternal intake of vitamin D during pregnancy may increase the risk of infantile eczema.

Another approach to prevent the appearance of allergic diseases inhigh risk pregnancy is to interfere with the immune system. In the antenatal period there are complex interactions between genes and the environment: epigenetics modifications that may modulate allergic sensitization in infancy and subsequently the development of allergic diseases. The fetal immune system may be exposed to early sensitizations that are provided by infections, environmental tobacco smoke, pollutants via the mother. The addition to the mother's diet of nutrients in particular of micronutrients such as prebiotics, vitamins, fatty acids and antioxidants could have an immune-modulatory effect and counteract the sensitization.

Few studies with omega 3 polyunsaturated fatty acid supplements in pregnancy have shown a reduction of children affected by allergic symptoms (food allergy) or in symptom severity (atopic dermatitis) ${ }^{[20]}$.

Two randomized controlled trials suggested that fish oil supplementation seems to reduce sensitization to $\operatorname{egg}^{[21,22]}$, although there was no supporting data on the prevention of food allergy ${ }^{[23]}$. In pregnant women with asthma an antioxidant-rich diet (that is, increased consumption of foods containing antioxidants as vegetables, fruit, whole grain), will lead to a reduced risk of low birth weight, growth failure, preterm delivery, and preeclampsia, by an improvement in asthma control; this will also potentially reduce the risk for atopic disease in childhood ${ }^{[24]}$.

\section{Lactation}

It has been described the possibility that mothers may accidentally sensitize children through breast milk but, two low-quality non randomized assessment studies found that maternal dietary avoidance during breastfeeding may not prevent food allergies in high-risk infants ${ }^{[25,26]}$.

One review identified many studies suggestive of a benefit from exclusive and non exclusive breast feeding ${ }^{[27]}$; in contrast, two cohort studies recommended that extended exclusive breast feeding may increase the chance of sensitization or food allergy in infants at high risk ${ }^{[28,29]}$.

In summary there is insufficient support that breast feeding has an impact on preventing food allergies in high-risk infants. Breast milk however has many other benefits and remains the gold reference in normal and high risk infants. Moreover recent finding have observed another immune-modulator activity of the breast milk: a possible transfer of exosomal micro RNA-155, which is important for the development of the immune system and controls pivotal target genes involved in the regulation of FoxP3+ and for the modulation the switch from Th2 to Th1 cytokine profile in the infant ${ }^{[30]}$.

\section{Infancy}

The possibility to prevent allergic diseases is oriented only to subjects with high risk conditions (i.e. with one or both parents and/or an older sibling with clear allergic manifestations such as atopic eczema/dermatitis, food allergy, allergic asthma, rhinitis. For these high riskinfants systematic reviews suggest that, in case of breast milk lacking during the first six months of life, an extensively hydrolyzed whey or casein formula may have a protective effect ${ }^{[27,31]}$ compared with standard CM formula. Also partially hydrolyzed infant formula appears to have a protective action $^{[32,33]}$. In contrast, no specific advices are addressed to infants without risk factors ${ }^{[1]}$. On the other hand, the trials with soy-based formulas do not give encouraging results on the protective effect against food allergies compared with $\mathrm{CM}$ formula or other alternative products ${ }^{[34]}$.

Despite of this, data are still conflicting above all concerning of the definition of target population who should be addressed with such preventive strategies. While almost all the guidelines on primary allergy prevention use to define as a "high risk infant" a child with one or both parents or a sibling with a documented allergic condition, this definition is still argued, since it seems to be widely inclusive and not taking into account the different grades of risk of each patients (e.g. the risk of a child with a only one parent with allergic rhinitis is not equivalent to one with a family history of multiple and severe allergic conditions $)^{[35]}$. The evidence of efficacy of the main primary allergy prevention strategies according to the most recent international guidelines is summarized in Table $3^{[1,35-37]}$.

Table 3: Evidence of efficacy of the main primary allergy prevention strategies according to the most recent International guidelines.

\begin{tabular}{|c|c|c|c|c|}
\hline \multirow[t]{2}{*}{ Intervention } & \multicolumn{4}{|c|}{ Recommendation } \\
\hline & $\mathrm{EAACI}^{[1]}$ & $\mathrm{AAP}^{[35]}$ & $\mathrm{CPS}^{[36]}$ & $\operatorname{ASCIA}^{[37]}$ \\
\hline $\begin{array}{l}\text { Maternal } \\
\text { avoidance } \\
\text { (pregnancy } \\
\text { and/or lacta- } \\
\text { tion) }\end{array}$ & $\begin{array}{l}\text { Dietary } \\
\text { restriction } \\
\text { are not } \\
\text { reco m - } \\
\text { mended }\end{array}$ & $\begin{array}{l}\text { No signifi- } \\
\text { cant benefit } \\
\text { to the chil- } \\
\text { dren with } \\
\text { materna } 1 \\
\text { avoidance }\end{array}$ & $\begin{array}{l}\text { Evidence to } \\
\text { support ma- } \\
\text { ternal dietary } \\
\text { restrictions is } \\
\text { contradictory } \\
\text { and insuffi- } \\
\text { cient }\end{array}$ & $\begin{array}{l}\text { Ex c } 1 \text { us i o n } \\
\text { of allergenic } \\
\text { foods from the } \\
\text { maternal diet } \\
\text { has not been } \\
\text { shown to pre- } \\
\text { vent }\end{array}$ \\
\hline $\begin{array}{l}\text { Exclusive } \\
\text { breast-feed- } \\
\text { ing (for } \\
\text { at least } 4 \\
\text { mo } \mathrm{n} \mathrm{th} \mathrm{s} \\
\text { and up to } 6 \\
\text { months) }\end{array}$ & YES & YES & YES & YES \\
\hline
\end{tabular}




\begin{tabular}{|c|c|c|c|c|}
\hline $\begin{array}{l}\text { Selection } \\
\text { of Infant } \\
\text { formula (in } \\
\text { case of lack- } \\
\text { ing of breast } \\
\text { milk) }\end{array}$ & & & & \\
\hline $\begin{array}{ll}\text {-No } & \text { risk } \\
\text { child } & \end{array}$ & $\begin{array}{l}\text { Standard } \\
\text { formula }\end{array}$ & $\begin{array}{l}\text { Evidence is } \\
\text { not conclu- } \\
\text { sive to sup- } \\
\text { port the use } \\
\text { of a special } \\
\text { formula }\end{array}$ & & \\
\hline $\begin{array}{l}\text {-High risk } \\
\text { child }\end{array}$ & $\begin{array}{l}\text { Should } \\
\text { receive } \\
\text { hypoal- } \\
\text { lergenic } \\
\text { formula } \\
\text { with doc- } \\
\text { umented } \\
\text { preven- } \\
\text { tive ef- } \\
\text { fect for } \\
\text { the first } 4 \\
\text { months }\end{array}$ & $\begin{array}{l}\text { A hy- } \\
\text { drolyzed } \\
\text { form u la } \\
\text { a p p e a r s } \\
\text { to offer ad- } \\
\text { vant a ges } \\
\text { eHF may } \\
\text { be slightly } \\
\text { more ben- } \\
\text { eficial than } \\
\text { pHF, but } \\
\text { data are in- } \\
\text { conclusive }\end{array}$ & $\begin{array}{l}\text { There is lim- } \\
\text { ited evidence } \\
\text { to suggest } \\
\text { hydrolyzed } \\
\text { f o r m u } 1 \text { a } \\
\text { in the } 4-6 \\
\text { months; eHF } \\
\text { of casein is } \\
\text { more likely } \\
\text { to be effec- } \\
\text { tive than pHF } \\
\text { of whey }\end{array}$ & $\begin{array}{l}\text { Hydrolyzed } \\
\text { formula may } \\
\text { reduce the risk } \\
\text { of allergic dis- } \\
\text { ease } \\
\text { In Australia } \\
\text { only pHF are } \\
\text { recommended } \\
\text { for allergy pre- } \\
\text { vention; eHF } \\
\text { are available } \\
\text { on prescription } \\
\text { for treatment } \\
\text { of CMA }\end{array}$ \\
\hline -Soy & $\begin{array}{l}\text { No evi- } \\
\text { dence to } \\
\text { support }\end{array}$ & $\begin{array}{l}\text { No advan- } \\
\text { tage }\end{array}$ & & $\begin{array}{l}\text { Not recom- } \\
\text { mended }\end{array}$ \\
\hline
\end{tabular}

AAP: American Academy of Pediatrics; ASCIA: Australasian Society of Clinical Immunology and Allergy; CMA: cow's milk allergy; CPS: Canadian Pediatric Society; eHF: extensive idrolyzed milk formula; EAACI: European Academy of Allergy and Clinical Immunology; pHF: partial idrolyzed milk formula.

\section{Other Possible Interventions: Dietary Supplements}

Specific non-digestible oligosaccharides (e.g. shortchain galacto-(scGOS) and long-chain fructo-(lcFOS) oligosaccharides), also known as prebiotics, exhibit some useful function of neutral oligosaccharides in human milk to modulate the immune system. Since also human milk contains acidic oligosaccharides, pectin-derived acidic oligosaccharides (pAOS) may be added to these neutral oligosaccharides to come close to the ratios found in human milk ${ }^{[38]}$. A systematic review found lacking evidence in the use of prebiotics in infant formula ${ }^{[39]}$. However in mice experimental model with CMA, a dietary intervention with a mixtures of scGOS and lcFOS alone or in addition to pAOS seems to prevent or treat CMA allergy ${ }^{[38]}$. Interestingly only the mixtures shows this benefit of reducing CMA symptoms, but not its single components alone. Both mixtures increased the number of functional regulatory $\mathrm{T}$ cells (Treg) Foxp3+ cells in the intestinal lamina propria of whey-sensitized mice, and selectively down-regulated Th2 and Th17 activation in the middle part of the small intestine. Oligosaccharides seem positively influence colonization of the gut with beneficial microbes such as bifidobacteria and lactobacilli in humans and mice, and have impact on the gut-associated lymphoid tissue and the systemic immune system.

Also systematic reviews on the use of probiotics found no evidence of preventive efficacy, perhaps probably due to the different strain studied that may have different properties ${ }^{[0,41]}$.

New perspective may arise from animal models: in mice experimental model protein fragments obtained by tryptic hydrolysis of $\beta$-lactoglobulin reduces the allergenic response of $\beta$-lactoglobulin ${ }^{[42]}$ and is associated with enhanced number of Foxp3+ regulatory T-cells in the mesenteric lymph nodes.

Recently it has also been found that combining a previous exposure to specific peptides of BLG with a diet containing a mixtures of scGOS, lcFOS and pAOS enhances the effect that involve regulatory and dendritic T cells ${ }^{[42]}$.

\section{Conclusions}

In conclusion, understanding the mechanisms underlying the pathogenesis of CMA has shown that many different factors can modulate the development of CMA; clinical and laboratory data suggest that many endotypes and phenotypes can be individuated with different evolutions towards tolerance. We need to identify these patterns in each child with CMA to better choose the therapeutic pathway together with the parents. The prevention of allergic diseases, in high risk infants (before 6 months of age) and when breast milk is lacking, may be obtained through the use extensive or partial Hydrolyzed milk formula, even if more robust data should be reported.

\section{Conflict of Interest: Author declare no conflicts of interest.}

\section{References}

1. Muraro, A., Halken, S., Arshad, S.H., et al. EAACI food allergy and anaphylaxis guidelines. Primary prevention of food allergy. (2014) Allergy 69(5): 590-601.

2. Høst A., Halken S. A prospective study of cow milk allergy in Danish infants during the first 3 years of life. Clinical course in relation to clinical and immunological type of hypersensitivity reaction. (1990) Allergy 45(8): 587-596.

3. Saarinen, K.M., Pelkonen, A.S., Mäkelä, M.J., et al. Clinical course and prognosis of cow's milk allergy are dependent on milk-specific IgE status. (2005) J Allergy Clin Immunol 116(4): 869-875.

4. Skripak, J.M., Matsui, E.C., Mudd, K., et al. The natural history of IgE-mediated cow's milk allergy. (2007) J Allergy Clin Immunol 120(5): 1172-1177.

5. Vanto, T., Helppilä, S., Juntunen-Backman, K., et al. Prediction of the development of tolerance to milk in children with cow's milk hypersensitivity. (2004) J Pediatr 144(2): 218-222.

6. Wood, R.A., Sicherer, S.H., Vickery, B.P., et al. The natural history of milk allergy in an observational cohort. (2013) J Allergy Clin Immunol 131(3): 805-812.

7. Hochwallner, H., Schulmeister, U., Swoboda, I., et al. Cow's milk allergy: from allergens to new forms of diagnosis, therapy and prevention. (2014) Methods 66(1): 22-33.

8. Allergome (2014).

9. Fiocchi, A., Brozek, J., Schünemann, H., et al. World Allergy Organization (WAO) Diagnosis and Rationale for Action against Cow's Milk Allergy (DRACMA) Guidelines. (2010) Pediatr Allergy Immunol 21(Suppl 21): 1-125.

10. Bellini F, Ricci G, Dondi A, et al. End point prick test: could this new test be used to predict the outcome of oral food challenge in children with cow's milk allergy? (2011) Ital J Pediatr 37: 52.

11. Kim, J.S., Nowak-Węgrzyn, A., Sicherer, S.H., et al. Dietary baked milk accelerates the resolution of cow's milk allergy in children. (2011) J Allergy Clin Immunol 128(1): 125-131.

12. Meglio, P., Bartone, E., Plantamura, M., et al. A protocol for oral desensitization in children with IgE-mediated cow's milk allergy (CMA). (2004) Allergy 59(9): 980-987.

13. Longo, G., Barbi, E., Berti, I., et al. Specific oral tolerance induction in children with very severe cow's milk-induced reactions. (2008) J Al- 
lergy Clin Immunol 121(2): 343-347.

14. Brożek, J.L., Terracciano, L., Hsu, J., et al. Oral immunotherapy for IgE-mediated cow's milk allergy: a systematic review and meta-analysis. (2012) Clin Exp Allergy 42(3): 363-374.

15. Kramer, M.S., Kakuma, R. Maternal dietary antigen avoidance during pregnancy or lactation, or both, for preventing or treating atopic disease in the child. (2012) Cochrane Database Syst Rev 9.

16. Bunyavanich, S., Rifas-Shiman, S.L., Platts-Mills, T.A., et al. Peanut, milk, and wheat intake during pregnancy is associated with reduced allergy and asthma in children. (2014) J Allergy Clin Immunol 133(5): 1373-1382.

17. Chiu, C.Y., Yao, T.C., Chen, S.H., et al. Low cord blood vitamin D levels are associated with increased milk sensitization in early childhood. (2014) Pediatr Allergy Immunol 25(8): 767-772.

18. Liao, S.L., Lai, S.H., Yeh, K.W., et al. Exclusive breastfeeding is associated with reduced cow's milk sensitization in early childhood. (2014) Pediatr Allergy Immunol 25(5): 456-461.

19. Miyake, Y., Tanaka, K., Okubo, H., et al. Maternal consumption of dairy products, calcium, and vitamin D during pregnancy and infantile allergic disorders. (2014) Ann Allergy Asthma Immunol 113(1): 82-87. 20. D'Vaz, N., Meldrum, S.J., Dunstan, J.A., et al. Postnatal fish oil supplementation in high-risk infants to prevent allergy: randomized controlled trial. (2012) Pediatrics 130(4): 674-682.

21. Furuhjelm, C., Warstedt, K., Larsson, J., et al. Fish oil supplementation in pregnancy and lactationmay decrease the risk of infant allergy. (2009) Acta Paediatr 98(9): 1461-1467.

22. Palmer, D.J., Sullivan, T., Gold, M.S., et al. Effect of n-3 long chain polyunsaturated fatty acidsupplementation in pregnancy on infants' allergies in first year of life: randomised controlled trial. (2012) BMJ 344: e184.

23. Noakes, P.S., Vlachava, M., Kremmyda, L.S., et al. Increased intake of oily fish in pregnancy: effects on neonatal immune responses and on clinical outcomes in infants at 6 mo. (2012) Am J Clin Nutr 95(2): 395-404.

24. Rosenlund, H., Magnusson, J., Kull, I., et al. Antioxidant intake and allergic disease in children. (2012) Clin Exp Allergy 42(10): 14911500 .

25. Lovegrove, J.A., Hampton, S.M., Morgan, J.B. The immunological and long-term atopic outcome of infants born to women following a milk-free diet during late pregnancy and lactation: a pilot study. (1994) Br J Nutr 71(2): 223-238.

26. Hattevig, G., Kjellman, B., Sigurs, N., et al. Effect of maternal avoidance of eggs, cow's milk and fish during lactation upon allergic manifestations in infants. (1989) Clin Exp Allergy 19(1): 27-32.

27. van Odijk, J., Kull, I., Borres, M.P., et al. Breastfeeding and allergic disease: a multidisciplinary review of the literature (1966-2001) on the mode of early feeding in infancy and its impact on later atopic manifestations. (2003) Allergy 58(9): 833-843.
28. Wetzig, H., Schulz, R., Diez, U., et al. Associations between duration of breast-feeding, sensitization to hens' eggs and eczema infantum in one and two year old children at high risk of atopy. (2000) Int J Hyg Environ Health 203(1): 17-21.

29. Mihrshahi, S., Ampon, R., Webb, K., et al. The association between infant feeding practices and subsequent atopy among children with a family history of asthma. (2007) Clin Exp Allergy 37(5): 671-679.

30. Melnik, B.C., John, S.M., Schmitz, G. Milk: an exosomal microRNA transmitter promoting thymic regulatory $\mathrm{T}$ cell maturation preventing the development of atopy? (2014) J Transl Med 12: 43.

31. Hays, T., Wood, R.A. A systematic review of the role of hydrolyzed infant formulas in allergy prevention. (2005) Arch Pediatr Adolesc Med 159(9): 810-816.

32. Osborn, D.A., Sinn, J. Formulas containing hydrolysed protein for prevention of allergy and food intolerance in infants. (2006) Cochrane Database Syst Rev (4): CD003664.

33. Szajewska, H., Horvath, A. Meta-analysis of the evidence for a partially hydrolyzed $100 \%$ whey formula for the prevention of allergic diseases. (2010) Curr Med Res Opin 26(2): 423-437.

34. Osborn, D.A., Sinn, J. Soy formula for prevention of allergy and food intolerance in infants. (2006) Cochrane Database Syst Rev 4: CD003741.

35. Fleischer, D.M., Spergel, J.M., Assa'ad, A.H., et al. Primary prevention of allergic disease through nutritional interventions. (2013) J Allergy Clin Immunol Pract 1(1): 29-36.

36. Chan, E.S., Cummings, C. Dietary exposures and allergy prevention in high-risk infants: A joint statement with the Canadian Society of Allergy and Clinical Immunology. (2013) Paediatr Child Health 18(10): 545-554.

37. Australasian Society of Clinical Immunology and Allergy 2014.

38. Kerperien, J., Jeurink, P.V., Wehkamp, T., et al. Non-digestible oligosaccharides modulate intestinal immune activation and suppress cow's milkallergic symptoms. (2014) Pediatr Allergy Immunol 25(8): 747-754.

39. Osborn, D.A., Sinn, J.K. Prebiotics in infants for prevention of allergy. (2013) Cochrane Database Syst Rev3:CD006474.

40. Osborn, D.A., Sinn, J.K. Probiotics in infants for prevention of allergic disease and food hypersensitivity. (2007) Cochrane Database Syst Rev (4):CD006475.

41. Tang, L.J., Chen, J., Shen, Y. Meta-analysis of probiotics preventing allergic diseases in infants. (2012) Zhonghua Er Ke Za Zhi50(7):504509.

42. Meulenbroek, L.A., van Esch, B.C., Hofman, G.A., et al. Oral treatment with $\beta$-lactoglobulin peptides prevents clinical symptoms in a mouse model for cow'smilk allergy. (2013) Pediatr Allergy Immunol 24(7):656-664
Online ISSN: 2377-0619

Journal Title: International Journal Food and Nutritional Science Journal Short Name: Int J Food Nutr Sci
Ommega Online Publishers

E-mail: editor.foodscience@ommegaonline.com

Website: www.ommegaonline.org 